\title{
Revista Brasileira de Educação Física e Esporte: 1986 - 2016
}

\author{
http://dx.doi.org/10.1590/1807-55092016000100005
}

Existem alguns aspectos que envolvem a Revista Brasileira de Educação Física e Esporte (RBEFE) e o ano de 2016 que merecem ser destacados nesse editorial. $\mathrm{O}$ primeiro e, talvez, afetivamente mais relevante para a comunidade científica é a comemoração do seu trigésimo aniversário. A RBEFE teve o primeiro número publicado no ano de 1986 após a aprovação de sua criação na $81^{\circ}$ Congregação da então Escola de Educaçáo Física da Universidade de São Paulo, a qual foi realizada em 31 de outubro de 1984. Nota-se que desde sua origem já havia a vocação para ser um meio de comunicação científica pautada na publicação de trabalhos com qualidade e relevância para a nossa área de atuação. Diversos passos importantes foram dados ao longo dessa trajetória, entre eles, a internacionalização do Conselho Editorial, a inclusão de Editores Associados oriundos das três áreas de concentração (Biodinâmica, Pedagogia e Sociocultural), a ampliação no número de pareceristas e a inclusão na base de periódicos eletrônicos da SciELO. Evidentemente, a pavimentação dessa longínqua estrada não poderia ter sido realizada sem a ajuda de muitos pesquisadores oriundos das mais variadas instituiçóes do Brasil e do exterior. Abaixo está o nome de algumas dessas pessoas que proporcionaram relevantes contribuiçóes para a consolidaçẫo da RBEFE. Lamento se, porventura, o nome de algum colega não tenha sido mencionado, em especial os revisores e autores de artigos publicados ou submetidos à publicaçáo. Não se trata de desprestígio ou algo que o valha, mas da nossa dificuldade em registrar o nome de tantas pessoas importantes que surgiram ao longo desses 30 anos. Existem outros profissionais que não se tornaram públicos ao longo desse processo, mas que sem o seu comprometimento, seguramente a RBEFE não teria atingido o prestigio atual. Estou me referindo as bibliotecárias e secretárias da revista: Maria Lúcia Vieira Franco, Solange Alves Santana. Exemplos de competência, ética e serenidade. À todos, o nosso muito obrigado!

Em relação à missão da RBEFE, sabemos que todo investimento financeiro realizado em pesquisa científica, incluindo do setor público, somente pode cumprir o seu papel social se os achados forem amplamente divulgados. Isso aumenta a nossa responsabilidade e nos leva a concluir que publicar um artigo é tão importante quanto conduzir as pesquisas científicas. Nesse sentido, desafios surgem a todo momento no horizonte das revistas que se propóem a inovar com o objetivo de atender as novas demandas impostas pela dinâmica que envolve a divulgação do conhecimento. Assim, 2016 também será um ano repleto de mudanças para a RBEFE. Isso se deve, sobretudo, a necessidade de adequarmos a revista aos novos critérios, política e procedimentos para a admissão e a permanência de periódicos científicos na coleção SciELO. A redução no tempo de avaliação e publicação dos artigos, a implementação de editores e pareceristas com afiliação estrangeira e a publicação de artigos na língua inglesa são algumas das açôes que deveremos implementar ao longo de 2016. Daremos início a essa implementação a partir da publicação do v.30 n.1, o qual foi coordenado pela Dra. Michele Viviene Carbinatto, do Departamento de Esporte da Escola de Educação Física e Esporte da Universidade de São Paulo e pela Dra. Myrian Nunomura, da Escola de Educaçáo Física e Esporte de Ribeirão Preto da Universidade de São Paulo. Nesse número foram publicados estudos que abordaram os mais variados temas que envolvem a "Ginástica", sendo uma parcela significativa $(-80 \%)$ dos artigos publicados em inglês. A nossa expectativa com essa mudança é ampliação do público da RBEFE, haja vista que a comunidade científica internacional elegeu o inglês como o idioma oficial para a sua comunicação. A SciELO estima que a publicação em inglês possa aumenta entre 4-6 vezes a possibilidade de um artigo ser citado quando comparado a um artigo publicado em português. Uma possível consequência dessa ampliação do público da RBEFE seria o aumento dos índices bibliométricos da revista, tal como o fator de impacto. Embora possamos destacar algumas limitaçóes acerca da utilização do fator de impacto como uma medida de qualidade, é inegável a importância que a maioria absoluta da comunidade científica internacional deposita nesse índice bibliométrico para a avaliação das revistas científicas. Assim, iniciamos essa nova fase com a expectativa que os próximos 30 anos serão tão frutíferos quanto os 30 anos que passaram.

\section{Prof. Dr. Rômulo Bertuzzi Editor-in-chief}




\section{Editores-chefe}

\author{
Alberto Carlos Amadio \\ Alexandre Moreira \\ Carlos Ugrinowitsch \\ Go Tani \\ Irany Novah Moraes \\ Jamil André \\ Marcos Duarte \\ Maria Augusta Peduti Dal'Molin Kiss \\ Raymond Victor Hegg \\ Rômulo Cássio de Moraes Bertuzzi \\ Umberto César Corrêa
}

\section{Editores de área}

$$
\begin{array}{r}
\text { Alexandre Moreira } \\
\text { Ana Cristina Zimmermann } \\
\text { Carlos Ugrinowitsch } \\
\text { Hamilton Roschel } \\
\text { Kátia Rubio } \\
\text { Luciano Basso } \\
\text { Umberto César Corrêa }
\end{array}
$$

\section{Editores Adjuntos}

\section{Guilherme Giannini Artioli Simonete Pereira da Silva Soraia Chung Saura}

\section{Conselho Editorial}

$$
\begin{array}{r}
\text { Alberto Carlos Amadio } \\
\text { Allen C. Parcell } \\
\text { Andrea Michele Freudenheim } \\
\text { Antônio Boaventura da Silva } \\
\text { Antônio Carlos Simóes } \\
\text { Antônio Carlos Stringhini Guimaräes } \\
\text { Antônio Herbert Lancha Junior } \\
\text { António Teixeira Marques } \\
\text { Carlos Eduardo Negräo } \\
\text { Dante De Rose Junior } \\
\text { David Gallabue } \\
\text { Edison de Jesus Manoel } \\
\text { Go Tani } \\
\text { Irany Novah Moraes } \\
\text { Jarbas Gonçalves } \\
\text { Jeong-su Kim } \\
\text { Jong Lee } \\
\text { José Angelo Barela } \\
\text { José Geraldo Massucato } \\
\text { José Guilmar Mariz de Oliveira } \\
\text { José Medalha } \\
\text { Kimberly Schimmel }
\end{array}
$$

Luiz Roberto Zuliani

Mack D. Rubley

Maria Alice Magalhães Navarro Maria Augusta Peduti Dal'Molin Kiss

Mark D. Ricard

Markus Vinicius Nahas

Moacyr Brondi Daiuto

Neil Fowler

Paulo de Aguiar Prouvot Paulo Sérgio Chagas Gomes

Richard Giulianotti Roberta Park Roland Renson

Rubens Lombardi Rodrigues

Sérgio Miguel Zucas Suely dos Santos

Valdir José Barbanti

\section{Comissáo de Publicação}

Alberto Carlos Amadio Alexandre Moreira

Ana Maria de Campos Lamim Andrea Michele Freudenheim

Carlos Eduardo Negrão Carlos Ugrinowitsch

Cecilia Ramadas Martins

Cláudia Lúcia de Moraes Forjaz

Claudia Maria Guedes

Dante De Rose Junior Divalierte Jorge

Edison de Jesus Manoel Jane Amaro Maciel Jorge Alberto de Oliveira José Medalha

Júlio Cerca Serrão Kátia Rubio

Luzimar Raimundo Teixeira Marcos Duarte Maria Augusta Peduti Dal'Molin Kiss Maria Lúcia Vieira Franco Maria Stella Vercesi Silva Olga Sakatsumi Martucci Osvaldo Luiz Ferraz

Patricia Chakur Brum Paulo Sérgio Chagas Gomes Selma Tripiciano Valdir José Barbanti Valmor Alberto Augusto Tricoli 